\title{
Development of Reinforcement Grout Materials Based on Blast Furnace Slag according to the Content of Reinforcement Fiber
}

\author{
H. Seo and D. H. Kim \\ Department of Civil Engineering, Chosun University, Gwangju 61452, Republic of Korea \\ Correspondence should be addressed to D. H. Kim; dkimgeo@chosun.ac.kr
}

Received 22 December 2020; Revised 13 June 2021; Accepted 21 September 2021; Published 19 October 2021

Academic Editor: Robert Černý

Copyright (C) 2021 H. Seo and D. H. Kim. This is an open access article distributed under the Creative Commons Attribution License, which permits unrestricted use, distribution, and reproduction in any medium, provided the original work is properly cited.

\begin{abstract}
The grouting is used to reinforce soft ground and to prevent the leakage of water in the soil. The objective of the study is to enhance the compressive strength of grout materials by using reinforcing fibers and to increase the strength of soil using blast furnace slag powder. For this purpose, cement was replaced with the blast furnace slag powder by 30 to $60 \%$. Furthermore, for comparison of carbon fibers with aramid fibers, each fiber was added by $0,0.5$, and $1.0 \%$ of the weight of material. As the contents of carbon fibers and aramid fibers increased, the uniaxial compressive strength increased. This is due to the interlocking of fibers in the grout material that increased the uniaxial compressive strength. Moreover, the grout material reinforced with aramid fibers showed an increase of uniaxial compressive strength by at least $20 \%$ compared to the carbon fibers. An environmental assessment was done through a heavy metal leaching test and a $\mathrm{pH}$ test. The test result reveals that about $50 \%$ of chromium (VI) leaching decreased as $30 \%$ more blast furnace slag powder was used but the $\mathrm{pH}$ test shows about $0.5 \mathrm{pH}$ increased as $30 \%$ more blast furnace slag powder was used. Further study is necessary for the $\mathrm{pH}$ test.
\end{abstract}

\section{Background and Objective}

The grouting method is generally used for reinforcing unstable slopes and stopping water leaks in embankments or dams. However, too much use of cement for grouting results in environmental contamination for living. An extensive effort is required for recycling the wastes and byproducts discharged from industries and reducing emitted carbon dioxide $\left(\mathrm{CO}_{2}\right)$.

To address this issue, although Choi [1] studied engineering characteristics of the eco-friendly SSG (self-healing smart grouting method), he could not exclude environmental contamination depending on the contents of sodium silicates for gel time, and Park [2] conducted the applicability test of biogrouting using eco-friendly microorganisms on sandy ground, but that was more expensive than OPC.

As described above, the ordinary Portland cement causing most environmental problems accounts for 3 to $7 \%$ of globally emitted $\mathrm{CO}_{2}$. Assuming that about 0.9 tons of carbon dioxide are emitted when producing one ton of cement, about 54 million tons of carbon dioxide are emitted every year in Korea because Korea produces about 60 million tons of cement every year. This accounts for $88.6 \%$ of emitted greenhouse gas contribution of Korea, indicating that cement substitutes should be developed in different sectors [3].

In this request, an increasing effort has been made to replace a given portion of cement with industrial byproducts. The blast furnace slag powder currently discussed is a typical byproduct discharged from the steel manufacturing process and discarded as industrial wastes but now used as aggregate for banking, bricks and aggregate for concrete, and a powdery admixture for concrete. In particular, the effort for developing the concrete without cement or construction materials using the reaction between the alkali stimulant and blast furnace slag will contribute to using the blast furnace slag as an eco-friendly material for resource circulation to conserve natural resources and reduce energy consumption and carbon dioxide [4]. 
Moreover, a property of materials including cement is vulnerable to tension and horizontal forces, and FRC (FiberReinforced Concrete) is used to address the issue. Although Romualdi and Gordon [5] identified the mechanism of the FRC method to prove its superiority, more studies are required to apply the method to grouting.

This study is to develop a reinforced grout material for reducing part of cement used by using blast furnace slag powder as a substitute to solve the problem in the ground environment and utilize $0.5 \%$ and $1.0 \%$ (in weight) of aramid fibers and carbon fibers as reinforcing fibers, respectively. This study aims to address some of the typical problems in grouting and to improve grouting method.

\section{Previous Studies}

The grouting method has been used in the construction industry in Korea since the construction of the Seoul Subway and the Busan Subway Projects in 1970s. After that period, various grouting methods including the LW method and the SGR method were introduced in Japan in 1980s and are used currently in many construction sites. In the 1990s, durability of chemical liquid was a concern to result in developing durable grout materials including colloidal silica sol. In the 2000s, the global environmental issues have emerged to develop eco-friendly liquid, for example, the no-cement or SSG method.

Recently, alkali-activated cements through alkali-activation reaction based on the blast furnace slag have been studied [6-9]. They are evaluated as a substitute of the ordinary Portland cement. The material, called an "alkaliactivated cement" or "geopolymer," is produced through alkali-activator's reaction between aluminosilicate-based raw materials, sodium silicate $\left(\mathrm{Na}_{2} \mathrm{SiO}_{3}\right)$, and sodium hydroxide $(\mathrm{NaOH})$ in the blast furnace slag.

The blast furnace slag contains a lot of $\mathrm{Ca}$ components and is mixed with fly ash and used for producing geopolymer to enhance its reaction and improve the performance of matrix [10-12]. It creates C-S-H gel and C-(A)-S-H similar to the hydrate of ordinary Portland cement at the early stage of reaction [13] and facilitates aluminosilicate gel formation of fly ash [14]. However, fast reaction of the blast furnace slag is a factor lowering flow performance and causing drying shrinkage [15].

In Korea, a few researchers have studied concrete produced by using the blast furnace slag powder and how to replace a given portion of cement with the blast furnace slag powder. The studies by Kim et al. [16] and Jeong et al. [17] about the blast furnace slag powder are mainly focused on how to use it simply as recycled aggregate. Many researchers have studied how to recycle strong aggregate in terms of cost effectiveness to develop eco-friendly mortar.

Moreover, many studies have focused on how to find ideal substitution ratios and powder levels of the blast furnace slag powder in order to analyze constructability and physical characteristics in construction sites. Jo [18], Jang and Ji [19], Han et al. [20], and Kim et al. [21] measured compressive strength and characteristics of the cement matrix depending on substitution ratios of cement and the blast furnace slag powder. The analysis shows a better flow and slightly less air with higher substitutions. Lower strength than ordinary cement in an initial stage was shown based on the 28th curing day, but there was equivalent or higher strength thereafter.

Lee [22] studied performance of concrete materials using the blast furnace slag powder and recycled coarse aggregate and conducted an experiment about engineering characteristics and durability of concrete using a lot of blast furnace slag powder.

Kim [23] substituted blast furnace slag powder as much as $20 \%$ and $40 \%$ and used carbon fibers to develop a grout material for cutoff. The uniaxial compressive strength test on homo-gel showed that more blast furnace slag powder contributed to less uniaxial compressive strength and more carbon fibers contributed to increasing the uniaxial compressive strength of specimen.

Fiber reinforcement refers to the method of mixing short and thin fibers randomly with cement-based or polymerbased materials to enhance bending, tensile strength, toughness, and energy absorption capability [24]. Reinforcement by mixing fibers with cement-based materials attracted people's attention while Romualdi and Batson proved the good point of FRC (Fiber-Reinforced Concrete) to enhance toughness in 1963 [8].

Many experimental studies have proved that steel fibers are a type of reinforcement material effective for enhancing bending, tensile strength, and toughness of cement composites $[25,26]$, and reinforcement performance depends on fiber shapes and mixing ratios. The characteristics of bonded steel fibers are a very important factor to fiber reinforcement [27, 28].

Recently, the method for bonding fibers has been studied for each fiber variable, and another study is being carried out about the method of reinforcing cement composites by using different types of fibers, in other words, hybrid steel fibers $[29,30]$.

As described above, most previous studies about using the blast furnace slag powder are about using it as a resource instead of recycling aggregate or cement in concrete and using it as a grout material should be further studied. Although several studies about reinforcing fibers proved better strength against tensile forces and bending in cement, using them as a grout material should be further studied. Therefore, this study aims to use the blast furnace slag powder as a cement substitute resource and develop a reinforced grout material for increasing tensile forces and horizontal forces and enhance seismic performance.

\section{Materials for Grouting Methods}

3.1. Overview of Grouting Method. The grouting method aims to inject a cement into the ground at a given pressure to improve the properties of ground. The injected liquid increases its strength and hardness while it is cured over time after injection. The strength and hardness after curing are shown to be different depending on various properties of components of injected materials, and different cement is injected for a desired purpose. 
The category of improved properties of ground by injection is classified into 4 types of cutoff for ground, reduced permeability, reduced ground deformation, and increased ground strength. The properties of injected material vary significantly with the characteristics of material (soil grain size, specific gravity, fineness, permeability coefficient, type of constituents, and mixing ratio, etc.) to exhibit very different permeability and reinforcement effects.

3.2. Reinforcing Fibers. A reinforcing fiber called a super fiber has a strength equal to or greater than the strength of metals, and exemplary reinforcing fibers include aramid fibers, carbon fibers, and flon fiber used as a composite material along with plastics or metals rather than used independently. They are called a fiber-reinforced metal or fiber-reinforced plastic. Typical super fibers include carbon fibers and para-aramid fibers.

Reinforcing fibers are required to meet strength of at least $20 \mathrm{~g} /$ denier and elasticity of at least $50 \mathrm{~g} /$ denier. The unit for yarn thickness that is shown for fibers is $\mathrm{g} /$ denier, and $1 \mathrm{~g} /$ denier is defined as $1 \mathrm{~g}$ per 9,000 $\mathrm{m}$ for yarn weight. $1 \mathrm{~g} /$ denier can be converted into SI units of $0.1111 \mathrm{~g} / \mathrm{km}$.

As describe above, Kim [31] studied reinforced concrete mixed with aramid fibers, and Yang [32] studied the reinforcement effect of the grouting method for using aramid fibers. Kim [33] studied a cutoff grouting method for using blast furnace slag and carbon fibers, but more studies are required about the hydration reaction and substitution with the blast furnace slag, as well as environmental assessment. Therefore, this study aims to address the issues and conduct comprehensive comparison and analysis of the carbon fibers and the aramid fibers.

3.3. Aramid Fibers. The aramid fibers were successfully developed to be a fiber with the strength of glass fibers and the thermal resistance of asbestos in 1965 is a synthetic fiber based on aromatic polymers and different from nylon of aliphatic polyamides. Aramid fibers are classified into the para-aramid fibers and meta-aramid fibers depending on the combination unit of combined aromatic rings. The metaaramid fibers are very good in terms of high-temperature resistance, and the para-aramid fibers are very elastic and strong. In particular, the elasticity of para-aramid fibers is 500 to $1,000 \mathrm{~g} /$ denier, and their tensile strength is at least $20 \mathrm{~g} /$ denier. Moreover, because the fibers' dissolution temperature is above $400^{\circ} \mathrm{C}$ and it can keep their characteristics as a fiber below $-160^{\circ} \mathrm{C}$, this implies very good cold and heat resistance, as well as high durability. Because the aramid fibers have different properties from other organic fibers and implement good performance cost-effectively, they are highvalue-added material. After the first industrialization, they have been used in various related industries, for example, industrial material purposes including bullet-proof and protective applications, ropes, composite materials, cables as a type of nonwoven fabrics, yarns, and textiles, as well as applications to information and communication, vehicles, national defense, and aerospace purposes [34].
3.4. Carbon Fibers. Carbon fibers refer to carbon material of fiber length made of carbon atoms accounting for at least $90 \%$ for the mass, and examples thereof are PAN-based carbon fibers and pitch-based carbon fibers depending on raw materials, and another example is cellulose-based carbon fibers. The PAN-based carbon fibers have properties of high strength and high elasticity through thermal stabilization and carbonization for precursors (polyacrylonitrile fibers) and are widely used for materials in the aerospace and other industries, sports, and leisure industry. The pitchbased carbon fibers are derived from carbonizing pitch precursors (coal tar or heavy oil-based pitch fibers) and can have different properties of low elasticity, high elasticity, and high strength depending on manufacturing conditions. Superelastic products are used for various applications because of high thermal and electric conductivity in addition to high strength [34].

Figure 1 shows the reinforced fibers used in the experiment.

Table 1 shows the physical properties of the fibers.

3.5. Blast Furnace Slag Powder. The blast furnace slag powder is a material of potential hydraulicity, and its curing is facilitated by the action of calcium hydroxide or sulfate when mixed with the Portland cement, although its curing property is not great to obtain properties not obtained from the Portland cement.

The blast furnace slag powder has advantages of reducing the speed of hydration heat generation, inhibiting rising concrete temperature, improving long-term strength, improving water tightness, inhibiting corrosion of reinforcing bars by preventing chloride-ion penetration, improving chemical resistance by sulfate, inhibiting alkali reaction, and facilitating flow. Therefore, it can be used as a mixing material to obtain ideal properties of concrete used. Although the blast furnace slag powder is generally used as blast furnace cement in Korea, it is necessary to use the ideal properties of blast furnace slag powder more efficiently and to design specifications of the blast furnace slag powder and use it as a mixing material for concrete.

\section{Laboratory Experiment}

4.1. Experiment of Uniaxial Compressive Strength of Grout Material. The purpose of grouting method is to inject a cement into the ground at a given pressure to improve the properties of ground. The injected liquid is cured over time to increase its strength and hardness after injection.

The sand-gel specimen to be measured in this study is composed of $80 \%$ of soil specimen and $20 \%$ of a grout material to measure the uniaxial compressive strength of soil specimen and thus evaluate the ground improvement material. Since a specimen is not formed when sodium silicate 3 for sand-gel is mixed with water but sodium silicate 3 lowers ground strength, sodium silicate 3 was not considered in this mixing ratio. It was expected that as the mixing ratio of aramid and carbon fibers as reinforcing fibers increases, the fibers in the specimen are combined 


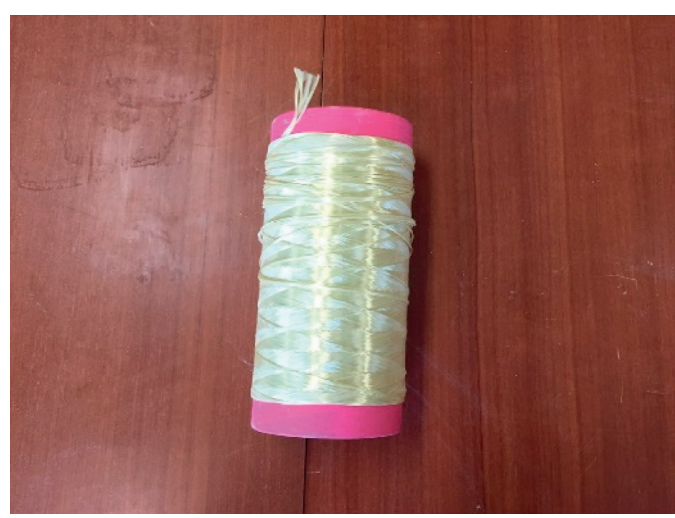

(a)

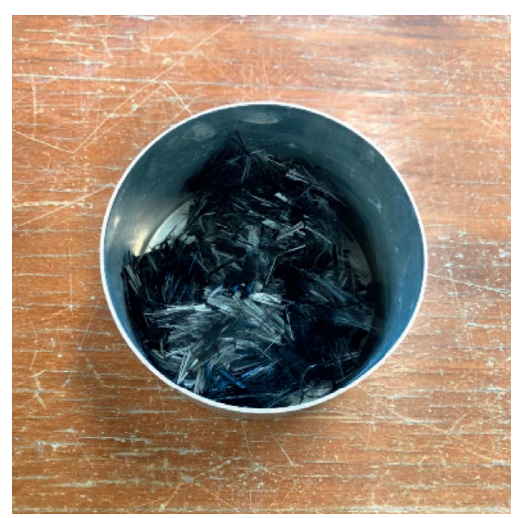

(b)

Figure 1: Experimental fiber: (a) aramid fiber; (b) carbon fiber.

TABle 1: Physical properties of general carbon fiber and aramid fiber.

\begin{tabular}{lcc}
\hline Classification & $\begin{array}{c}\text { Aramid fiber } \\
\text { (g/denier) }\end{array}$ & $\begin{array}{c}\text { Carbon fiber } \\
\text { (g/denier) }\end{array}$ \\
\hline $\begin{array}{l}\text { Tensile strength } \\
\text { Modulus of elasticity }\end{array}$ & 20 & $20 \sim 45$ \\
$500 \sim 1000$ & $1400 \sim 3000$ \\
\hline
\end{tabular}

with the cement to function as threaded reinforcing bars to enhance resistance. It was also expected that the increasing surface oiling ratio contributes to improving fiber dispersion capability, implying effectiveness in preventing fibers from being lumped and thus controlling cracks. The specimen was prepared as follows. All the ingredients were prepared and mixed carefully. After that, they were poured into the mold and compacted five layers. Therefore, the specimens were produced with the same unit weight.

The sand is classified as SW (well-graded silica sand) according to the Unified Soil Classification System (USCS) and the particle size distribution curve is shown in Figure 2. For this experiment, sand was weathered soil, OPC (ordinary Portland cement) was cement, slag (blast furnace slag powder) was blast furnace slag fine powder, $\mathrm{Ca}(\mathrm{OH})_{2}$ was calcium hydroxide, and $W$ was water.

Tables 2 and 3 illustrate the mixing ratios for measuring the uniaxial compressive strength of sand-gel for each fiber type. As shown in Table 2, some fibers were added to liquid B (combination of materials) which is the combination of OPC, blast furnace slag powder, calcium hydroxide, and water. This grout can be injected into the ground like a typical permeation grout method. Generally, $0.5 \%$ of fiber is used for reinforcing fiber groutings. So, we utilized $0.5 \%$ of aramid fiber and $1.0 \%$ of carbon fiber as reinforcing fibers to investigate the effects of mixing rate on the strength of the grout. When using grouting methods, heterogeneity in the field is generally a concern. This may not be considered in laboratory element experiments and this should be further investigated in the field.

The mold used in this study is a round mold sized $5 \mathrm{~cm}$ (D) $\times 10 \mathrm{~cm}(\mathrm{H})$ for which the ratio of diameter to height was $1: 2$. The experiment mold was made of cast iron, and the lubricant was applied thinly to the inner side of the mold to minimize specimen deformation in the process of mold removal.

The injected material was mixed and shaped in the prepared mold according to the mixing ratio. The specimen was removed from the mold 24 hours after putting the injected material in the mold and 3 specimens were air-dried for curing for $3,7,14$, and 28 days to get averages. For the analysis of the results, the number of specimens used in the experiment was 192 in the case of aramid fiber and 108 in the case of carbon fiber, and a total of 300 specimens were destroyed.

Figure 3 shows the process of uniaxial compression experiment test.

4.2. SEM and EDX Experiment. Figure 4 shows an SEM (scanning electron microscope) used as an instrument for SEM analysis. The SEM can examine behaviors of soil particles in the specimen, and an analysis was conducted to compare behaviors of the nontreated specimen with those of soil particles containing aramid and carbon fibers as reinforcing fibers.

EDX (energy dispersive X-ray spectrometer) can show the atoms appearing on the surface of soil particles and examine chemical changes of the soil particles, and EDX was used to compare $\mathrm{Si}$ and $\mathrm{Ca}$ contents in the fine powder of blast furnace slag according to the mixing ratio.

4.3. Environmental Assessment. Although there is a growing concern about environmental harms including alkali $(\mathrm{pH})$ and heavy metals $\left(\mathrm{Cr}^{6+}\right)$ because of grout materials releasing toxic materials, there is no established method for testing the toxic material leaching from grout materials at present in Korea. Most methods for testing heavy metal leaching provide regulations about landfill wastes, complying with the KSLP (Korea Standard Leaching Procedure) for examining whether the wastes are included in the specified wastes.

4.4. Testing Heavy Metal Leaching. The KSLP as a standard for testing material leaching was applied to testing the heavy metals. The specimen was produced by crushing the water 


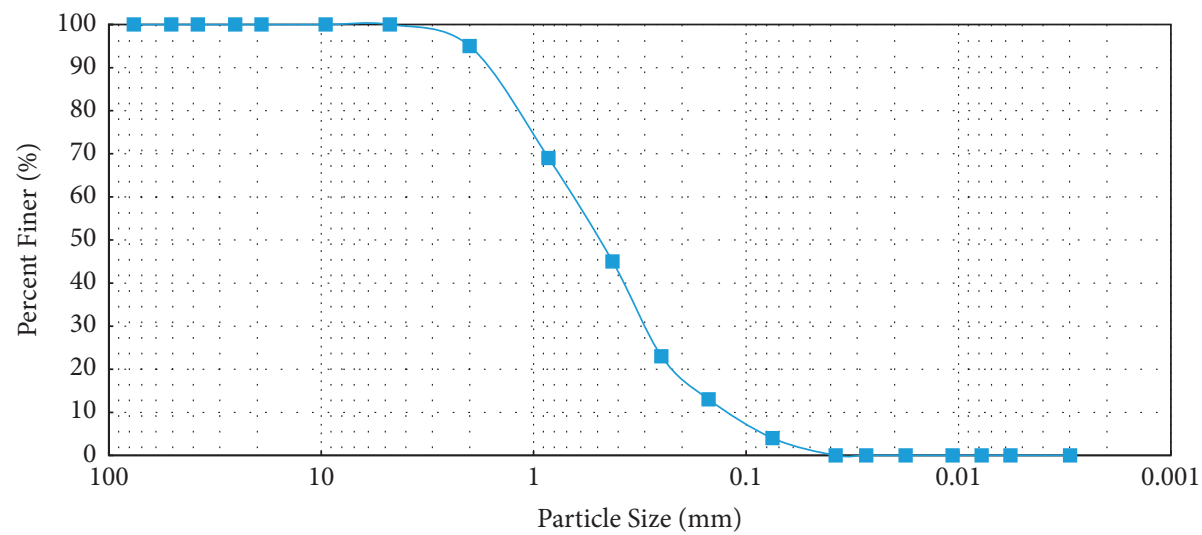

Figure 2: Particle size distribution curve of sand.

TABle 2: Mixing ratio for measurement of uniaxial compression strength of grout materials using aramid fiber.

\begin{tabular}{lcccccc}
\hline A & \multicolumn{3}{c}{ B liquid } & \multicolumn{2}{c}{ Fiber } \\
Sand & $\begin{array}{c}\text { OPC } \\
(\mathrm{g})\end{array}$ & $\begin{array}{c}\text { Slag } \\
(\mathrm{g})\end{array}$ & $\begin{array}{c}\mathrm{Ca}(\mathrm{OH})_{2} \\
(\mathrm{ml})\end{array}$ & $\begin{array}{c}\text { Water } \\
(\mathrm{ml})\end{array}$ & $\begin{array}{c}\text { Oiling agent } \\
(\%)\end{array}$ & $\begin{array}{c}\text { Aramid } \\
(\mathrm{g})\end{array}$ \\
\hline & 70 & 0 & 0 & 50 & & 0.7 \\
& $(100 \%)$ & $(0 \%)$ & & & & 0.35 \\
350 & 49 & 21 & 21 & 29 & & $\begin{array}{c}0.5 \%) \\
\\
\end{array}$ \\
& $(70 \%)$ & $(30 \%)$ & & & 1.2 & 0.7 \\
& $(40 \%)$ & $(60 \%)$ & 42 & 8 & & $(1.0 \%)$ \\
\hline
\end{tabular}

TABLE 3: Mixing ratio for measurement of uniaxial compression strength of grout materials using carbon fiber.

\begin{tabular}{lccccc}
\hline A & \multicolumn{5}{c}{ B liquid } \\
Sand $(\mathrm{g})$ & $\begin{array}{c}\text { OPC } \\
(\mathrm{g})\end{array}$ & $\begin{array}{c}\text { Slag } \\
(\mathrm{g})\end{array}$ & $\begin{array}{c}\mathrm{Ca}(\mathrm{OH})_{2} \\
(\mathrm{ml})\end{array}$ & $\begin{array}{c}\text { Water } \\
(\mathrm{ml})\end{array}$ & $\begin{array}{c}\text { Fiber } \\
\text { Carbon } \\
(\mathrm{g})\end{array}$ \\
\hline \multirow{4}{*}{350} & 70 & 0 & 0 & 50 & $0 \%$ \\
& $(100 \%)$ & $(0 \%)$ & & & 0.35 \\
& 49 & 21 & 21 & 29 & $\begin{array}{c}0.5 \%) \\
\end{array}$ \\
& $(70 \%)$ & $(30 \%)$ & & & 0.7 \\
& 28 & 42 & 42 & 8 & $(1.0 \%)$ \\
\hline
\end{tabular}

glass-based caking specimen so that it can pass through the $2 \mathrm{~mm}$ sieve after drying at $105^{\circ} \mathrm{C}$ for one hour because of the moisture in the specimen after caking. After the preparation process, the specimen was preprocessed according to the method for preparing specimens by taking at least $100 \mathrm{~g}$ of prepared specimen to mix it with the solvent $(\mathrm{ml})$ made by putting hydrochloric acid in distilled water to implement $\mathrm{pH}$ between 5.8 and 6.3 at the ratio of $1: 10(W: V)$ in a $200 \mathrm{ml}$ Erlenmeyer flask.

After the specimen was shaken continuously for 6 hours by means of a shaker of which the amplitude/shaking/ minute is about 4 to $5 \mathrm{~cm}$ for shaking it about 200 times at room temperature and the atmospheric pressure, the mixture was filtered with a $1.0 \mu \mathrm{m}$ glass fiber filter. The filtered liquid was preprocessed to conduct the heavy metal detection test.
4.5. $p H$ Test. As the aramid fibers and the carbon fibers as reinforcing fibers in the specimen are not related to $\mathrm{pH}$ like the heavy metal leaching test, the $\mathrm{pH}$ test was conducted with an increase in the contents of blast furnace slag powder. Therefore, the mixing ratios of $C: B 100: 0,70: 30$, and 40 : $60 \%$ were analyzed, and contamination of the harmful water leaching into the ground was measured to examine the effect of grout materials used for cutoff and ground reinforcement.

For $\mathrm{pH}$ analysis, the specimen was immersed in water for 30 minutes to measure $\mathrm{pH}$ for the initial stage, $0.5,1,3,6,12$, 24 , and 48 hours as illustrated.

\section{Findings from Experiment}

5.1. Findings from Testing Uniaxial Compressive Strength of Sand-Gel. The purpose of grouting method is to inject a cement into the ground at a given pressure to improve the properties of ground. The injected liquid is cured over time to increase its strength and hardness after injection.

\subsubsection{Results from Testing Uniaxial Compressive Strength} according to Mixing Ratio of OPC:B. As shown in Figure 5(a), the uniaxial compressive strength over time was analyzed in $C: B$ of $100: 0,70: 30$, and $40: 60 \%$ for the nontreated specimen, showing the lowest strength of $3.35 \mathrm{MPa}$ for $100: 0 \%$ and the highest strength of $3.86 \mathrm{MPa}$ for $C: B$ of $40: 60 \%$ on the 3 rd curing day. The strength on the 28th curing day was the lowest, $4.91 \mathrm{MPa}$, for $C: B$ of $100: 0 \%$, and the highest, $6.71 \mathrm{MPa}$, for $C: B$ of $40: 60 \%$.

Figures 5(b) to 5(e) show the lowest strength for $C: B$ of $100: 0$ but the highest strength for $C: B$ of $40: 60 \%$ on the 3 rd and 28th curing days.

The thin film surrounding the surface of blast furnace slag powder was removed with calcium hydroxide ions to raise long-term hydration heat, and this contributed to enhancing long-term strength depending on the contents of blast furnace slag powder, which is different from previous studies.

5.1.2. Result of Testing Uniaxial Compressive Strength Depending on Each Fiber and OPC:B Mixing Ratio. Figure 6 presents the uniaxial compressive strength over time according to fiber contents. As the mixing ratios of the 


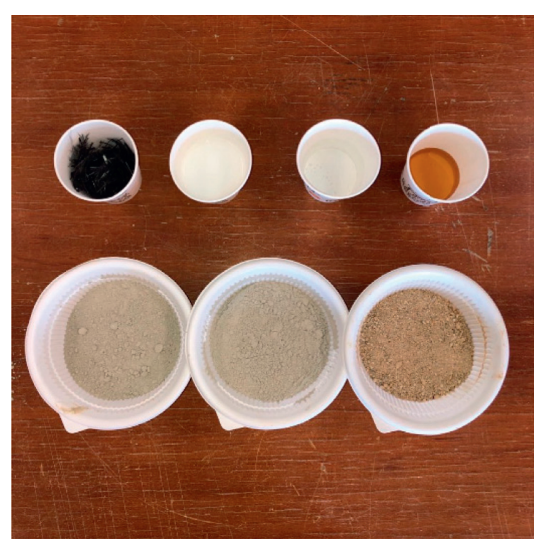

(a)

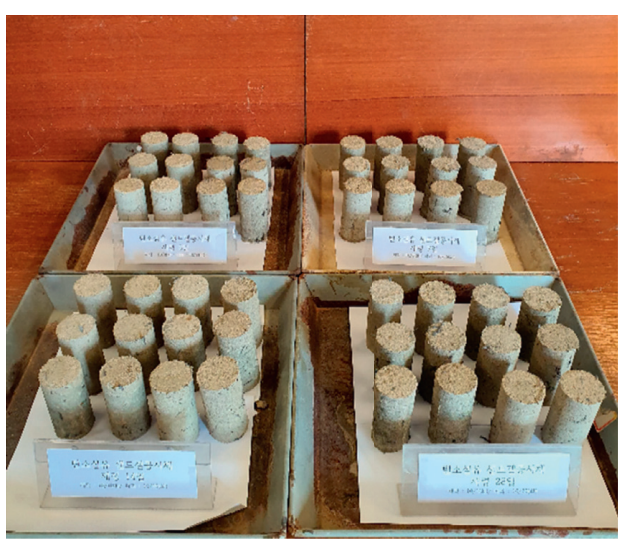

(b)

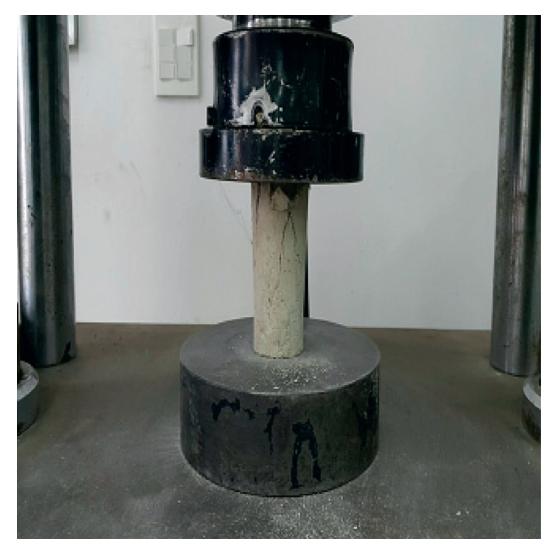

(c)

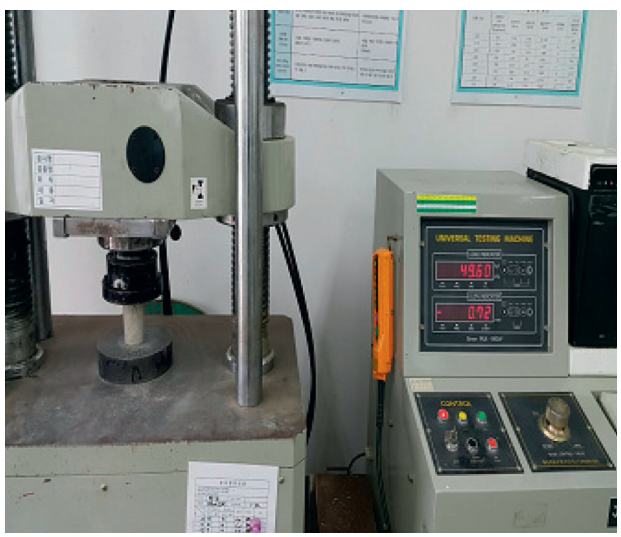

(d)

Figure 3: Process of uniaxial compression test: (a) material mixing; (b) aerial curing; (c) uniaxial compression test; (d) shape of test specimens after test.

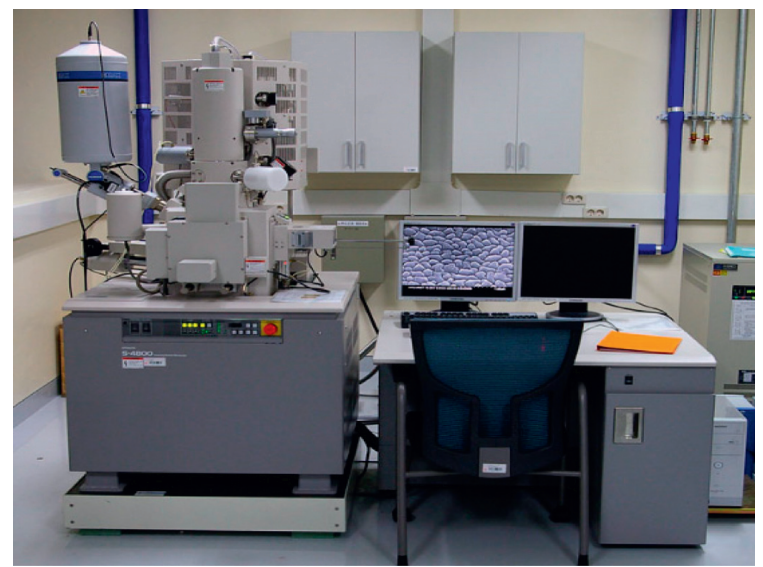

Figure 4: ScanningElectron Microscope.

aramid fibers and the carbon fibers increased by $0.5 \%$, the uniaxial compressive strength was high on all of $3 \mathrm{rd}, 7 \mathrm{th}$, 14 th, and 28th curing days. This implies that better bonding between cement and fibers tackles the stress by axial load in the specimen. Furthermore, the aramid fibers showed high uniaxial compressive strength on all of $3 \mathrm{rd}$, 7 th, $14 \mathrm{th}$, and 28 th curing days with an increase of $0.5 \%$ in the surface oiling rate, implying that surface oiling made aramid fibers flow better to contribute to raising the capability of fiber dispersion and thus uniform mixing in the specimen.

When OPC: $B$ was $40: 60 \%$, the nontreated specimen showed the highest strength of 6.71 MPa on the 28th curing day, and the specimen with carbon fibers showed 7.48 $\mathrm{MPa}$, but the specimen with aramid fibers showed $8.09 \mathrm{MPa}$ as fibers increased as much as $1.0 \%$, suggesting $0.77 \mathrm{MPa}$ and $1.38 \mathrm{MPa}$ higher than the nontreated specimen, respectively.

Table 4 shows the results of the test for uniaxial compressive strength of the sample according to the mixing ratio and curing period.

\subsection{SEM and EDX Analysis}

5.2.1. Uniaxial Compressive Strength according to Mixing Ratio of OPC:B. The SEM test is conducted to examine the mechanism of combination between aramid fibers, cement, and blast furnace slag powder in the grout material depending on the properties of reinforcing fibers. The material specimen detached in measuring the uniaxial compressive strength was used to analyze the nontreated specimen without reinforcing fibers of $C: B 100: 0 \%$ and the specimen mixed with $1.0 \%$ of aramid fibers for $C: B 100: 0 \%$. Figure $7(\mathrm{a})$ shows a photo of the specimen without reinforcing fibers for $C: B$ 100:0\% taken with an SEM at 


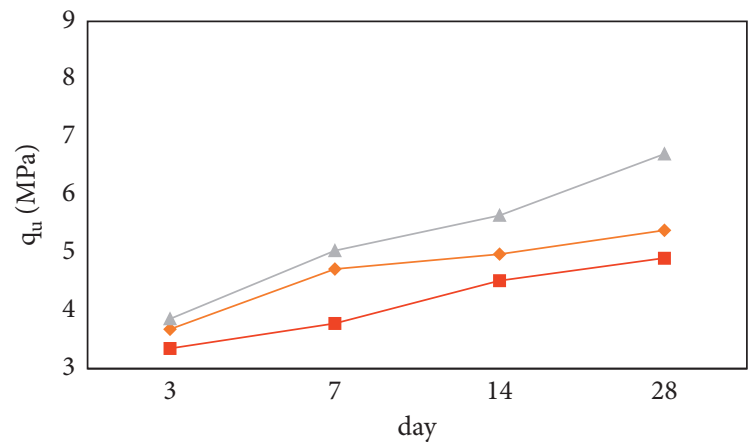

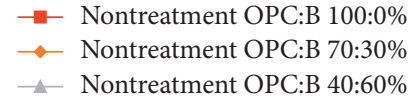

(a)

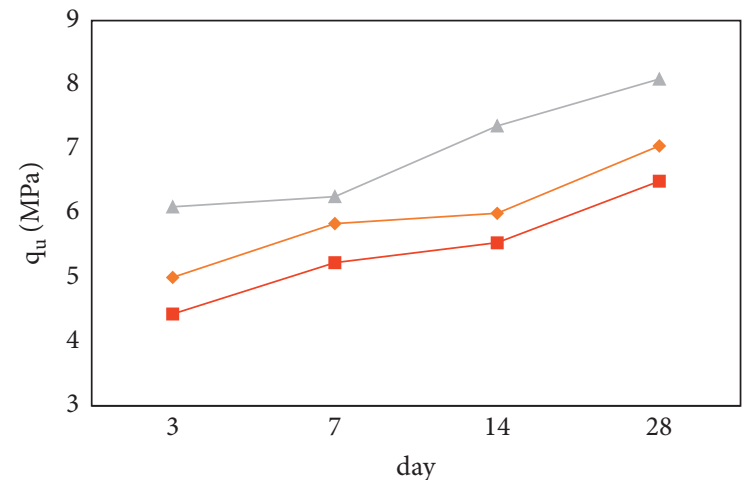

- O:A $1.2: 1.0 \%$, OPC:B 100:0\%
$\longrightarrow-$ O:A $1.2: 1.0 \%$, OPC:B 70:30\%
$\rightarrow-$ O:A $1.2: 1.0 \%$, OPC:B 40:60\%

(c)

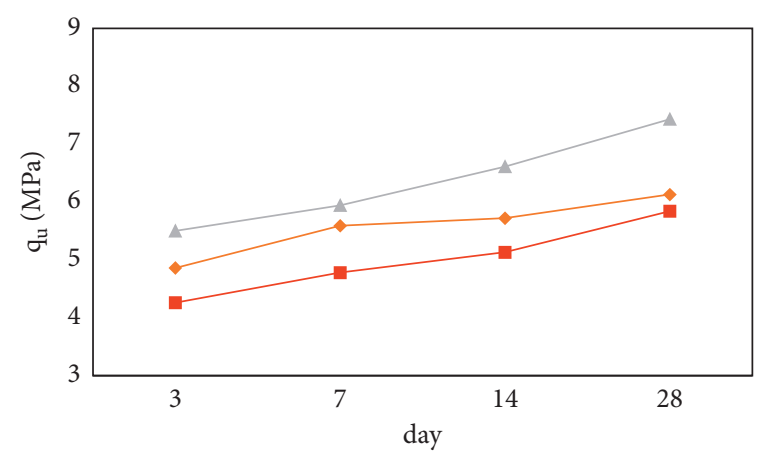

O:A $1.2: 0.5 \%$, OPC:B 100:0\%

$\longrightarrow$ O:A $1.2: 0.5 \%$, OPC:B 70:30\%

— O:A 1.2 : 0.5\%, OPC:B 40:60\%

(b)

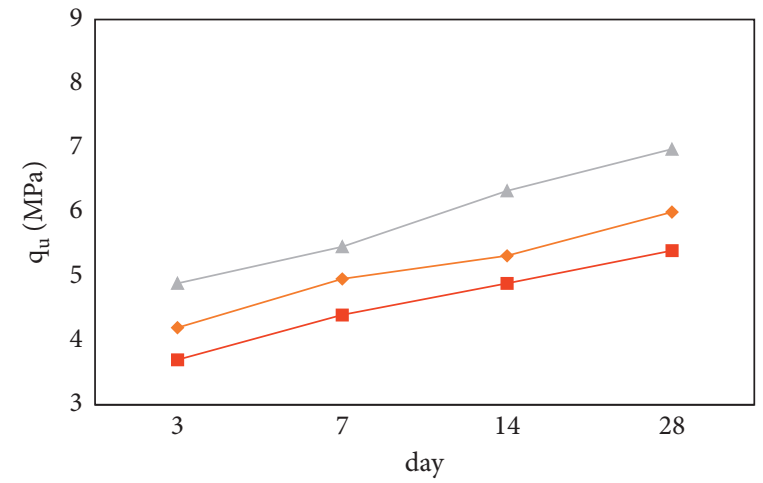

C : 0.5\%, OPC:B 100:0\%

C : $0.5 \%$, OPC:B 70:30\%

$\rightarrow$ C : $0.5 \%$, OPC:B 40:60\%

(d)

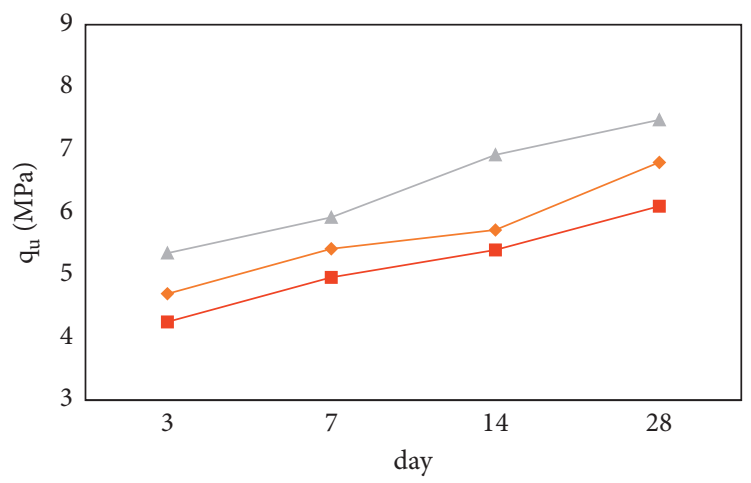

- $-\mathrm{C}: 1.0 \%$, OPC:B 100:0\%

— C: $1.0 \%$, OPC:B 70:30\%

A C : $1.0 \%$, OPC:B 40:60\%

(e)

FIgURe 5: Analysis of uniaxial compressive strength by $C: B$ mixing ratios: (a) results of uniaxial compression test from nontreated specimen; (b) results of uniaxial compression test for $O: A=1.2: 0.5 \%$; (c) results of uniaxial compression test for $O: A=1.2: 1.0 \%$; (d) results of uniaxial compression test for $C=0.5 \%$; (e) results of uniaxial compression test for $C=1.0 \%$.

magnification of 250x, and Figure 7(b) shows a photo of the specimen surface at magnification of 500x. It is shown that many grains were piled on the specimen surface, and they were identified cement fragments.
The specimen containing $1 \%$ of aramid fibers for $C: B$ 100:0\% was analyzed with an SEM to show the specimen surface at 100x and 500x, shown in Figures 8(a) and 8(b). As shown in Figure 8, because the cured specimen in which the 


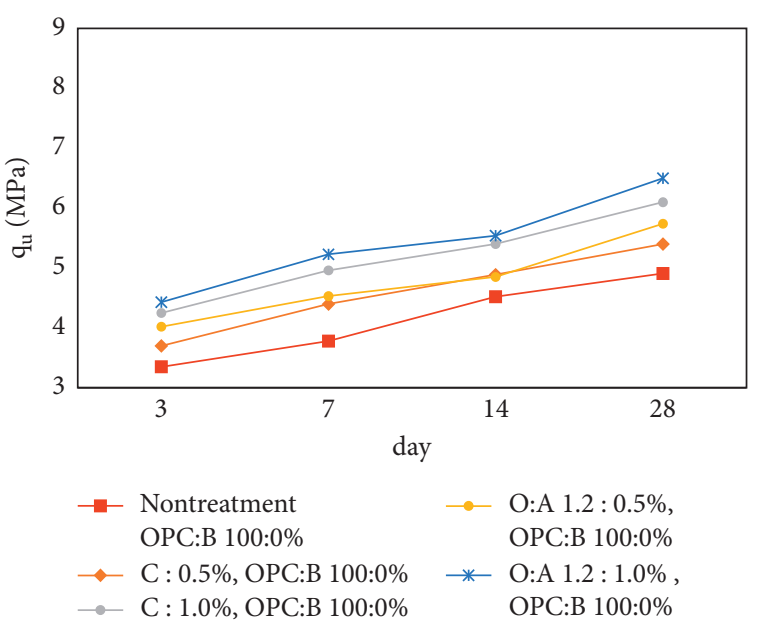

(a)

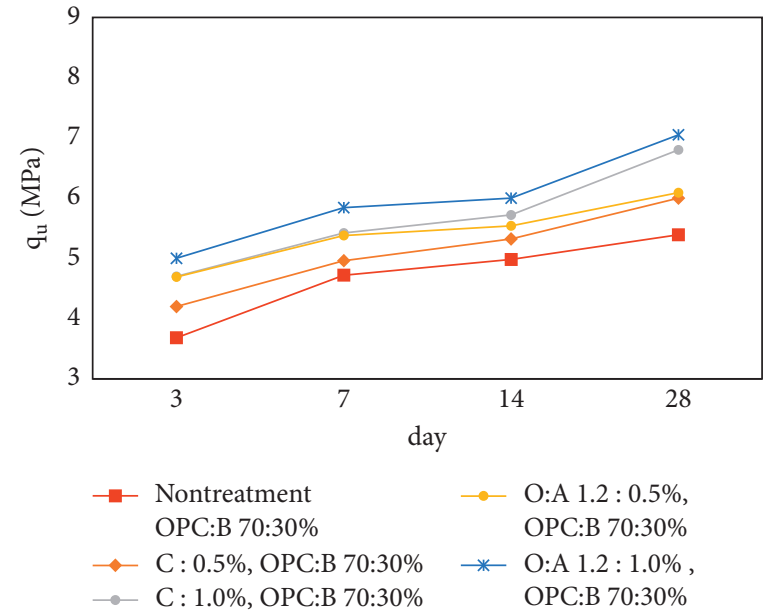

(b)

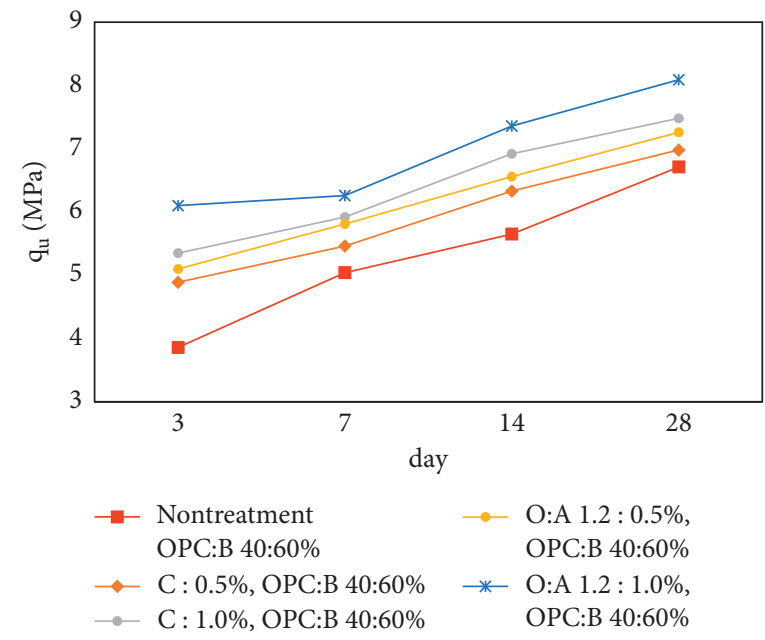

(c)

Figure 6: Analysis of uniaxial compressive strength by fiber contents: (a) results of uniaxial compressive test for OPC:B=100:0\%; (b) results of uniaxial compressive test for OPC: $B=70: 30 \%$; (c) results of uniaxial compressive test for OPC:B=40:60\%.

aramid fibers were combined with the grout material behaves as one body with the aramid fibers, the fibers in the specimen function as threaded reinforcing bars in shear fracture of the specimen to resist on the shear failure plane and thus increase the compressive strength, as confirmed by Figure 6.

5.3. EDX Analysis. The specimen crushed after measuring the uniaxial compressive strength was sampled to conduct the EDX analysis. Because the findings were different depending on the sampling locations, the sample was taken from 3 locations of one specimen for measuring uniaxial compressive strength to use the average.

The EDX analysis reveals that the main components of this mixing ratio are $\mathrm{O}$ (oxygen), $\mathrm{C}$ (carbon), $\mathrm{Ca}$ (calcium), and $\mathrm{Si}$ (silicon). Furthermore, it was identified that the elements of $\mathrm{Al}$ (aluminum), $\mathrm{Mg}$ (magnesium), and $\mathrm{Na}$ (sodium) in the contents less than $10 \%$ were from the cement and the blast furnace slag powder.
As illustrated in Tables 5 to 7 , more blast furnace slag powder resulted in more Si and $\mathrm{Ca}$. It is considered that more contents of blast furnace slag powder with a great specific surface area increased contents of Si and Ca because the cement and the blast furnace slag powder are composed of similar minerals.

\subsection{Environmental Assessment}

5.4.1. Analysis of Leaching Test. Most methods for analyzing, evaluating, and testing heavy metal leaching comply with the KSLP (Korea Standard Leaching Procedure) in Korea. Korea adopts 10 for LSR (Liquid Solid Ratio) which is a ratio of specimen leaching to solvent leaching, and 6 hours are specified for leaching time.

The heavy metal leaching test showed 0.467 for $C: B$ of $100: 0 \%$ and 0.092 for $C: B$ of $40: 60$. Moreover, as $30 \%$ more blast furnace slag powder was used, about $50 \%$ of chromium (VI) tended to decrease. It is considered that the heavy metal 
TABLE 4: Results of uniaxial compressive strength test of sand-gel.

\begin{tabular}{|c|c|c|c|c|c|}
\hline \multicolumn{2}{|c|}{ Classification } & \multicolumn{4}{|c|}{ Uniaxial compressive strength $(\mathrm{MPa})$} \\
\hline Fiber contents & OPC $: B$ & 3rd day & 7th day & 14th day & 28 th day \\
\hline \multirow{3}{*}{ Nontreated specimen } & $100: 0 \%$ & 3.35 & 3.78 & 4.52 & 4.91 \\
\hline & $70: 30 \%$ & 3.68 & 4.72 & 4.98 & 5.39 \\
\hline & $40: 60 \%$ & 3.86 & 5.04 & 5.65 & 6.71 \\
\hline \multirow{3}{*}{$\mathrm{O}: A=0.7: 0.5 \%$} & $100: 0 \%$ & 3.63 & 4.39 & 4.72 & 5.14 \\
\hline & $70: 30 \%$ & 4.47 & 5.03 & 5.22 & 5.75 \\
\hline & $40: 60 \%$ & 4.66 & 5.48 & 6.24 & 7.22 \\
\hline \multirow{3}{*}{$\mathrm{O}: A=0.7: 1.0 \%$} & $100: 0 \%$ & 4.26 & 4.78 & 5.13 & 5.84 \\
\hline & $70: 30 \%$ & 4.86 & 5.59 & 5.72 & 6.13 \\
\hline & $40: 60 \%$ & 5.50 & 5.94 & 6.61 & 7.43 \\
\hline \multirow{3}{*}{$\mathrm{O}: A=1.2: 0.5 \%$} & $100: 0 \%$ & 4.02 & 4.53 & 4.85 & 5.74 \\
\hline & $70: 30 \%$ & 4.69 & 5.38 & 5.54 & 6.09 \\
\hline & $40: 60 \%$ & 5.10 & 5.81 & 6.56 & 7.26 \\
\hline \multirow{3}{*}{$\mathrm{O}: A=1.2: 1.0 \%$} & $100: 0 \%$ & 4.43 & 5.23 & 5.54 & 6.50 \\
\hline & $70: 30 \%$ & 5.00 & 5.84 & 6.00 & 7.05 \\
\hline & $40: 60 \%$ & 6.10 & 6.26 & 7.36 & 8.09 \\
\hline \multirow{3}{*}{$C=0.5 \%$} & $100: 0 \%$ & 3.70 & 4.40 & 4.89 & 5.40 \\
\hline & $70: 30 \%$ & 4.20 & 4.96 & 5.32 & 6.00 \\
\hline & $40: 60 \%$ & 4.89 & 5.46 & 6.33 & 6.98 \\
\hline \multirow{3}{*}{$C=1.0 \%$} & $100: 0 \%$ & 4.25 & 4.96 & 5.40 & 6.10 \\
\hline & $70: 30 \%$ & 4.70 & 5.42 & 5.72 & 6.80 \\
\hline & $40: 60 \%$ & 5.35 & 5.92 & 6.92 & 7.48 \\
\hline
\end{tabular}

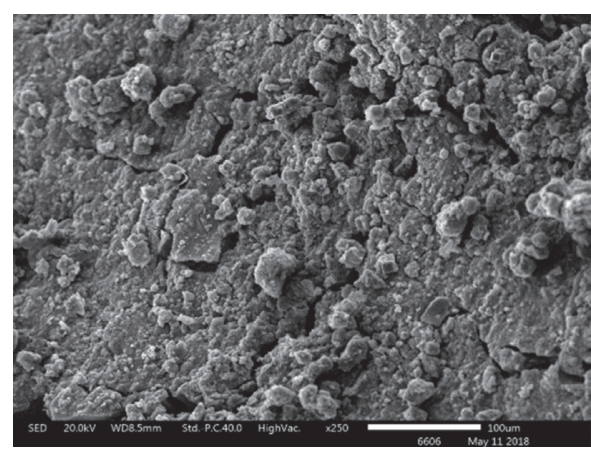

(a)

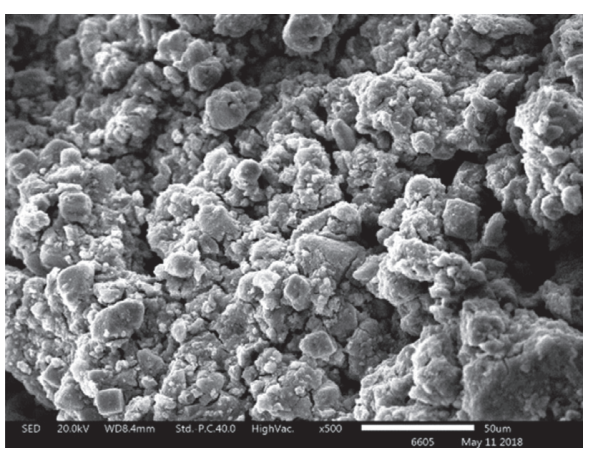

(b)

Figure 7: SEM photos without fibers: (a) specimen surface, 250x; (b) specimen surface, 500x.

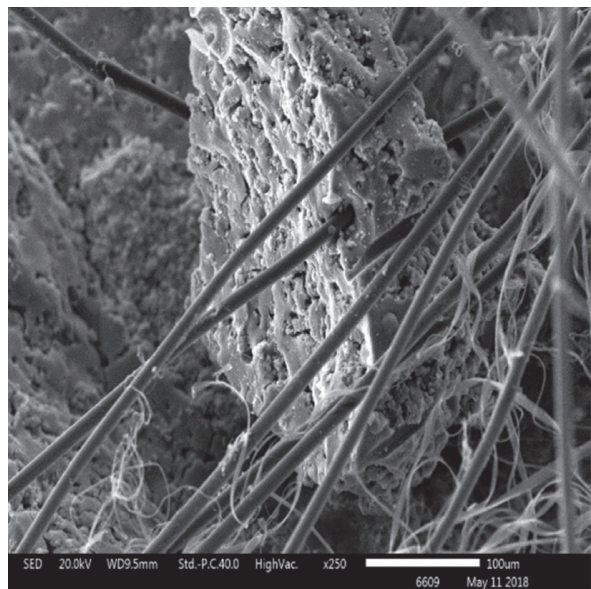

(a)

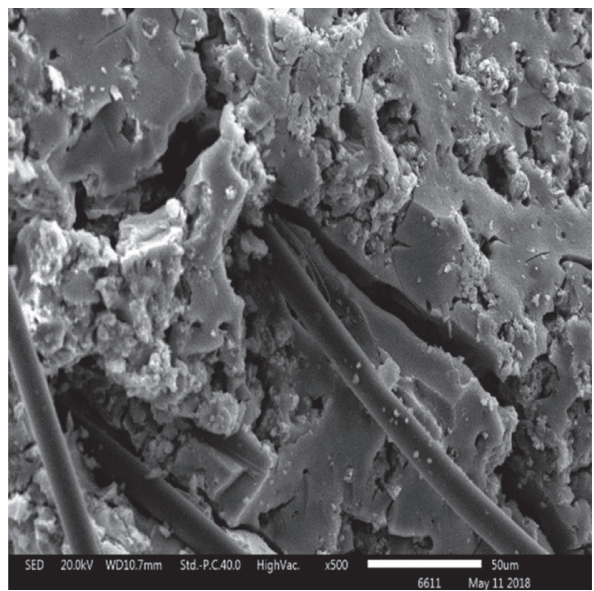

(b)

Figure 8: Continued. 


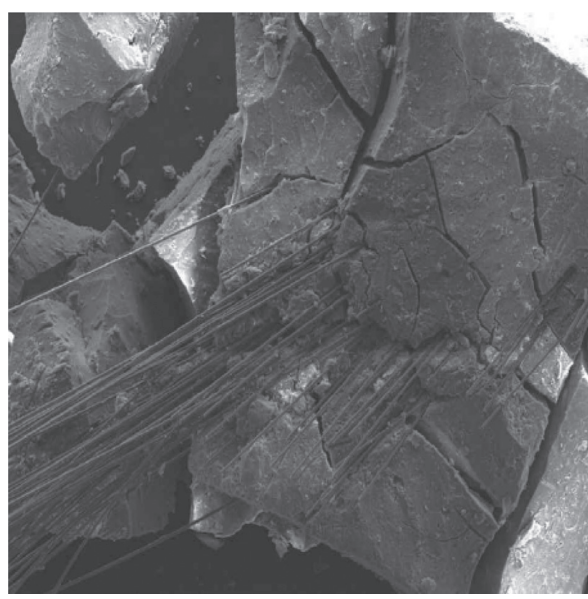

(c)

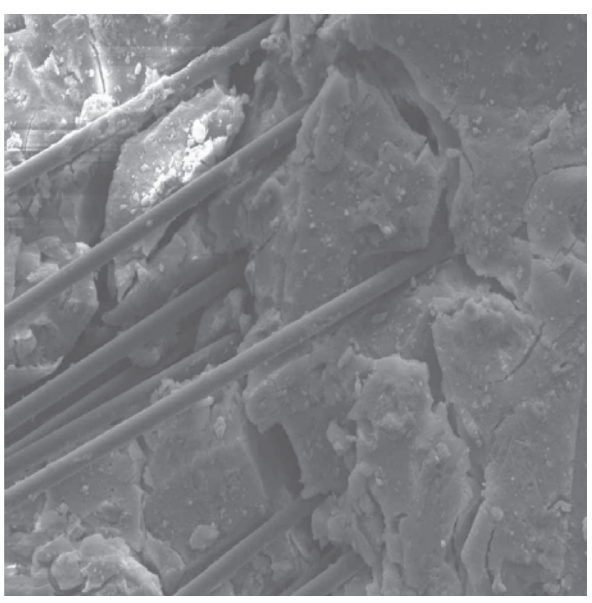

(d)

FIGURE 8: SEM photos of reinforcing fibers: (a) specimen reinforced with a large amount of aramid fibers (250x); (b) specimen reinforced with a large amount of aramid fibers (500x); (c) sample reinforced with a large amount of carbon fibers (250x); (d) sample reinforced with a large amount of carbon fibers (500x).

TABLE 5: Findings from EDX analysis for $C: B$ of $100: 0 \%$.

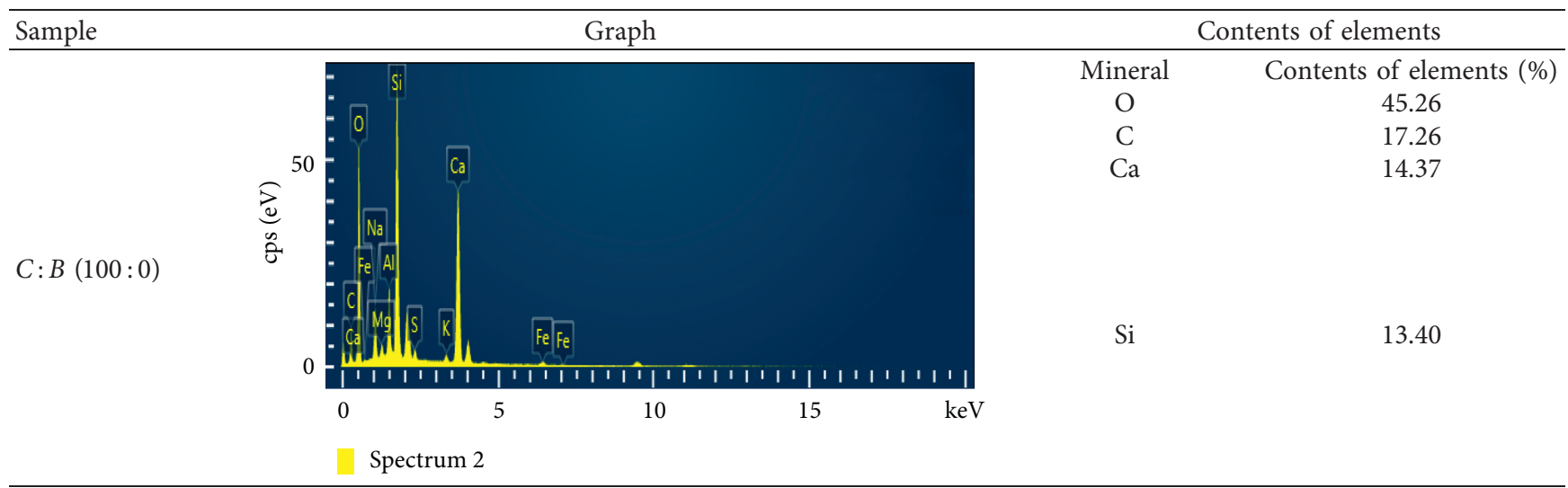

TABLE 6: Findings from EDX analysis for $C: B$ of $40: 30 \%$.

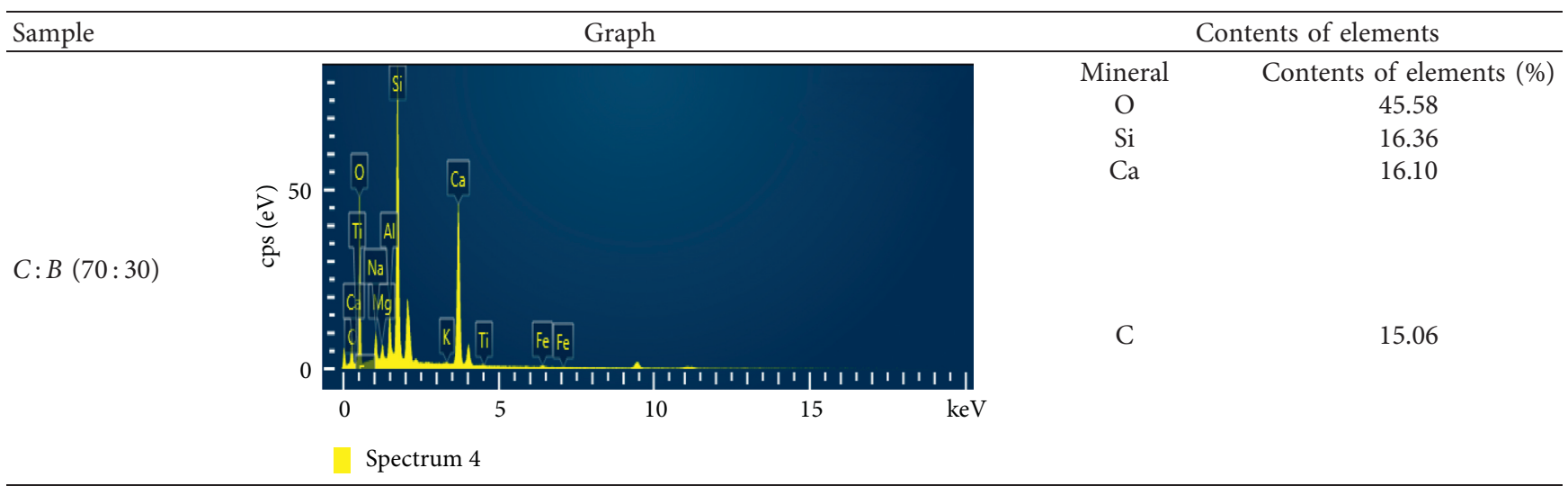


TABLE 7: Findings from EDX analysis for C:B of $40: 60 \%$.

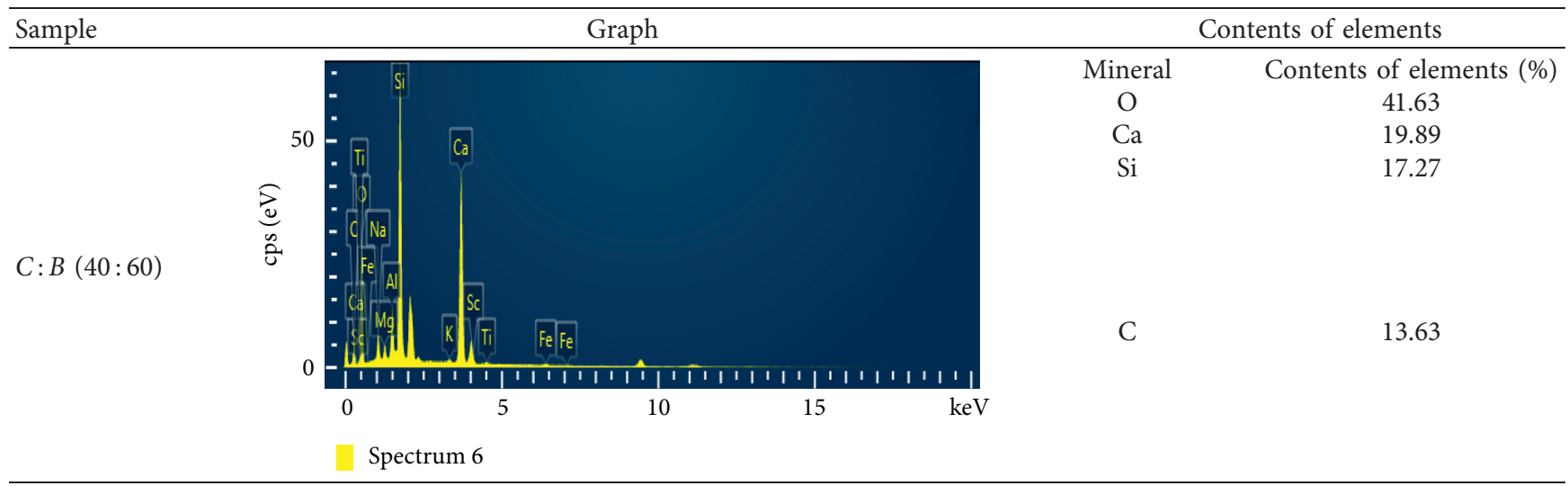

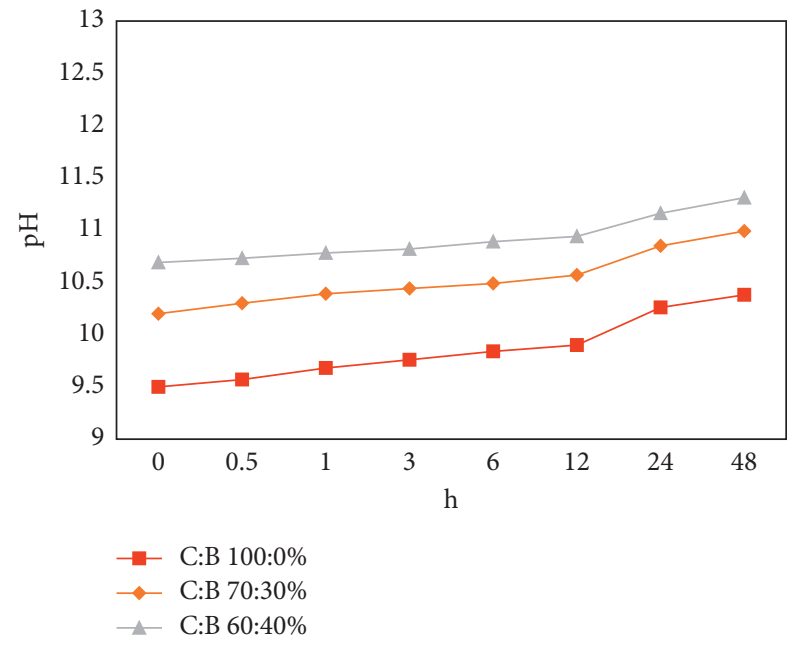

Figure 9: Findings from $\mathrm{pH}$ test.

components in the Portland cement and the blast furnace slag powder were fixed through hydration reaction and then chemical coupling to result in slight leaching of the heavy metals. Although the heavy metal leaching test in the conventional LW method is different, Oh (2015) argues the LW method showed 0.662 which means smaller leaching of heavy metals than conventional methods.

As a very little amount of heavy metal (chromium (VI)) leaching smaller than the standard of harmful heavy metal leaching specified in the Waste Control Act as a harmful substance leaching standard was observed, it was identified that the harmful impact on the environment was not great.

5.4.2. Analysis of $\mathrm{pH}$ Test. The tendency of alkali $(\mathrm{pH})$ elution characteristics of the specimen is shown in Figure 9. For $C: B$ of $100: 0 \%$, the $\mathrm{pH}$ test showed 10.38 after 48 hours, 10.89 for $C: B$ of $70: 30 \%$, and 11.31 for $C: B$ of $40: 60 \%$, implying that $\mathrm{pH}$ increased by 0.5 as $30 \%$ more blast furnace slag powder was used. This means greater specific surface areas increased the $\mathrm{pH}$ levels because of the small diameter of blast furnace slag powder. Therefore, it is necessary to use plasticizers in consideration of the impact on the environment to inhibit $\mathrm{pH}$ rise and reduce heavy metal leaching through antiwashout capability of the grout material for cutoff.

\section{Conclusions}

This study aims to develop a reinforced grout material of ideal compressive strength by mixing aramid and carbon fibers as reinforcing fibers with blast furnace slag powder and cement. For the mixing ratios of mixed materials, the uniaxial compressive strength (3rd, 7th, 14th, and 28th curing days) of sand-gel as a grout material was measured for each fiber. SEM and EDX analysis and environmental assessment were conducted depending on mixed materials to evaluate and verify the basic performance of the grout material to be developed. The conclusions drawn from the study are as follows:

(1) The uniaxial compressive strength of sand-gel was measured to show the highest on the 3rd and 28th days for $C: B$ of $40: 60 \%$. Moreover, when $1 \%$ of carbon fibers were added, the uniaxial compressive strength increased by about $10 \%$ and by more than $20 \%$ when $1 \%$ of aramid fibers were added to imply that the aramid fibers and the carbon fibers as reinforcing fibers were effective as a reinforcing material in the sand-gel to enhance durability.

(2) The SEM analysis reveals that the integrated behaviors of the reinforcing fibers in the grout material contributed to an enough increase in strength. Furthermore, the EDX analysis reveals that more blast furnace slag powder contributed to increasing $\mathrm{Si}$ and $\mathrm{Ca}$ contents, implying that this is attributable to an increase in the amount of blast furnace slag powder with great specific surface areas.

(3) The leaching test for environmental assessment exhibits that chromium (VI) leaching as one of leaching heavy metals decreased by about $50 \%$ as $30 \%$ more blast furnace slag powder was used. It appears that the heavy metal components were fixed through chemical coupling and hydration reaction between the cement and the blast furnace slag powder. 
(4) The $\mathrm{pH}$ test reveals that $\mathrm{pH}$ increased by about 0.5 as $30 \%$ more blast furnace slag powder was used, implying that the small diameter of the blast furnace slag powder to result in greater specific surface areas increased $\mathrm{pH}$. It is necessary to further study the environment for $\mathrm{pH}$ to use the antiwashout material depending on site conditions.

\section{Data Availability}

The data used to support the findings of this study are available from the corresponding author upon request.

\section{Conflicts of Interest}

The authors declare that they have no conflicts of interest.

\section{Acknowledgments}

This study was supported by Chosun University, 2021.

\section{References}

[1] Y. S. Choi, An Experimental Study on the Engineering Properties of Self-Healing Eco-Friendly Grout Material, Myongji University, Korea, Doctor's Degree, 2016.

[2] K. H. Park, Evaluation of Applicability of Environment Friendly Biogrouting Methods in Loose Frictional Soils, Chosun University, Korea, Doctor's Degree, 2015.

[3] T. B. Park, Physio-Chemical Characteristics of Slag Based ZeroCement Grout, Myongji University, Korea, Master's Degree, 2017.

[4] H. J. Hyeon, An Experimental Study on the Properties of the Cementless Lightweight Aerated Concrete with Blast Furnace Slag, Konkuk University, Korea, Master's Degree, 2017.

[5] J. P. Romualdi and B. Gordon, "Mechanics of crack arrest in concrete," Journal of Engineering Mechanics-ASCE, vol. 89, no. EM3, pp. 147-168, 1963.

[6] B. Talling and J. Brandstetr, "Present state and future of alkali activated slag concretes," American Concrete Institute, vol. 114, pp. 1519-1546, 1989.

[7] T. Bakharev, J. G. Sanjayan, and Y.-B. Cheng, "Alkali activation of Australian slag cements," Cement and Concrete Research, vol. 29, no. 1, pp. 113-120, 1999.

[8] D. Hardjito, S. E. Wallahm, D. M. Sumajouwm, and B. V. Ranganm, "On the development of fly ash based geopolymer concrete," Materials Journal, vol. 101, no. 6, pp. 467-472, 2004.

[9] A. A. Adam, I. Patnaikuni, D. W. Law, and T. C. K. Molyneaux, "Strength of mortar containing activated slag and fly ash: design materials and construction," in Proceedings of the 23rd Biennial Conference of the Concrete Institute of Australia, Concrete for future, Adelaide, Australia, October 2007.

[10] C. Shi, D. Roy, and P. Krivenko, Alkali-Activated Cements and Concretes, Other Alkali Activated Cementitious System, CRC Press, Boca Raton, Florida 2005.

[11] M. Guerrieri and J. G. Sanjayan, "Behavior of combined fly ash/slag-based geopolymers when exposed to high temperaturesm," Fire and Materials, vol. 34, no. 4, pp. 163-175, 2010.

[12] J. E. Oh, P. J. M. Monteiro, S. S. Jun, S. Choi, and S. M. Clark, "The evolution of strength and crystalline phases for alkaliactivated ground blast furnace slag and fly ash based geopolymers," Cement and Concrete Research, vol. 40, no. 2, pp. 189-196, 2010.

[13] S. K. Nath and S. Kumar, "Influence of iron making slags on strength and microstructure of fly ash geopolymer," Construction and Building Materials, vol. 38, pp. 924-930, 2013.

[14] S. A. Bernal, R. Mejía de Gutiérrez, and J. L. Provis, "Engineering and durability properties of concretes based on alkaliactivated granulated blast furnace slag/metakaolin blends," Construction and Building Materials, vol. 33, pp. 99-108, 2012.

[15] N. Marjanović, M. Komljenović, Z. Baščarević, V. Nikolić, and R. Petrović, "Physical-mechanical and microstructural properties of alkali-activated fly ash-blast furnace slag blends," Ceramics International, vol. 41, no. 1, pp. 1421-1435, 2015.

[16] Y. H. Kim, C. G. Han, and H. J. Lee, "Effect of recycled fine aggregate powder and opc on the strength gain properties of mortar using blast furnace slag powder and natural aggregates," Journal of the Architectural Institute of Korea, vol. 29, no. 3, pp. 81-88, 2013.

[17] J.-Y. Jeong, S.-Y. Jang, Y.-C. Choi, S.-H. Jung, and S.-I. Kim, "Effects of replacement ratio and fineness of ggbfs on the hydration and pozzolanic reaction of high-strength highvolume GGBFS blended cement pastes," Journal of the Korea Concrete Institute, vol. 27, no. 2, pp. 115-125, 2015.

[18] S. G. Jo, "An experimental study on the workability and engineering properties of concrete using ground granulated blast furnace slag," Journal of The Society of Convergence Knowledge, vol. 1, no. 1, pp. 43-50, 2013.

[19] H. O. Jang and N. O. Ji, "An experimental study on the mixing of strength and high fluidity concrete using ground granulated blast furnace slag," Journal of the Architectural Institute of Korea, vol. 29, no. 6, pp. 81-88, 2013.

[20] C. G. Han, S. H. Kim, and H. J. Son, "Engineering characteristics analysis of high strength concrete followed in replacement ratio increase in blast furnace slag," Journal of the Korean Recycled Construction Resources Institute, vol. 7, pp. 62-68, 2009.

[21] J.-H. Kim, M.-C. Han, and C.-G. Han, "Strength development of the concrete incorporating blast furnace slag and recycled aggregate as alkali activator," Journal of the Korean Recycled Construction Resources Institute, vol. 2, no. 2, pp. 107-114, 2014.

[22] H. H. Lee, "Material capacity evaluation of concrete using blast furnace slag powder and recycled coarse aggregate," Architectural Institute of Korea Fall Conference, vol. 36, no. 2, pp. 1523-1524, 2016.

[23] H. C. A. Kim, Study on the Development of a Grouting Material Containing Blast Furnace Slag and Carbon Fiber, Chosun University, Korea, Doctor's Degree, 2018.

[24] S. P. Shah, "Fiber reinforced concrete," Handbook of Structural Concrete, vol. 1, pp. 1-14, 1984.

[25] S. P. Shah and B. V. Rangan, "Fiber reinforced concrete properties," ACI journal, vol. 68, no. 2, pp. 126-135, 1971.

[26] P. Soroushian and Z. Bayasi, "Fiber type effects on the performance of steel fiber reinforced concrete," Materials Journal, vol. 88, no. 2, pp. 129-134, 1991.

[27] J. Gao, W. Sun, and K. Morino, "Mechanical properties of steel fiber-reinforced, high-strength, lightweight concrete," Cement and Concrete Composites, vol. 19, no. 4, pp. 307-313, 1997.

[28] A. E. Naaman, "Engineered steel fibers with optimal properties for reinforcement of cement composites," Journal of Advanced Concrete Technology, vol. 1, no. 3, pp. 241-252, 2003. 
[29] N. Banthia and M. Sappakittipakorn, "Toughness enhancement in steel fiber reinforced concrete through fiber hybridization," Cement and Concrete Research, vol. 37, no. 9, pp. 1366-1372, 2007.

[30] S.-T. Kang, J.-I. Choi, K.-T. Koh, K. S. Lee, and B. Y. Lee, "Hybrid effects of steel fiber and microfiber on the tensile behavior of ultra-high performance concrete," Composite Structures, vol. 145, pp. 37-42, 2016.

[31] Y. W. Kim, Containing Aramid Fiber Reinforced Concrete Research, Kyungpook National University, Korea, Master's Degree, 2010.

[32] Y. H. Yang, Evaluation of Reinforcement Effect of Grouting Using Aramid Fiber, Chosun University, Korea, Master's Degree, 2017.

[33] H. C. A. Kim, Study on the Development of a Grouting Material Containing Blast Furnace Slag and Carbon Fiber, Chosun University, Korea, Doctor's Degree, 2017.

[34] M. G. Seo and S. J. Park, "Carbon fiber manufacturing methods and applications," Polymer Science and Technology, vol. 21, no. 2, pp. 130-140, 2010. 